\title{
Attitude toward Safety among Staffs in the Iranian Maternity Care Units of Public Hospitals with High Maternal Death Rate, 2015-2016
}

\author{
Nahid Akbari ${ }^{*}$, Marzieh Malek ${ }^{2}$, Shima Haghani ${ }^{3}$ \\ ${ }^{1}$ Midwifery and Reproductive Health, School of Nursing and Midwifery, Iran University of Medical Sciences, Tehran, Iran \\ ${ }^{2}$ School of Nursing and Midwifery, Iran University of Medical Sciences, Tehran, Iran \\ ${ }^{3}$ Department of Biostatistics, School of Management and Information Technology, Iran University of Medical Sciences, Tehran, \\ Iran \\ Email: *Akbari1420@gmail.com
}

How to cite this paper: Akbari, N., Malek, M. and Haghani, S. (2017) Attitude toward Safety among Staffs in the Iranian Maternity Care Units of Public Hospitals with High Maternal Death Rate, 2015-2016. Open Journal of Obstetrics and Gynecology, 7, 386-394. https://doi.org/10.4236/ojog.2017.73040

Received: January 12, 2017

Accepted: March 26, 2017

Published: March 29, 2017

Copyright $\odot 2017$ by authors and Scientific Research Publishing Inc. This work is licensed under the Creative Commons Attribution International License (CC BY 4.0).

http://creativecommons.org/licenses/by/4.0/

\begin{abstract}
Background: Although extensive Mother-friendly Hospital initiatives have been improved the quality of maternity care in Iran, recent national reports have been indicated that obstetrics errors are still common. The current study aimed to assess safety attitude in the maternity care units of public hospitals in a region with high rate of maternal death in Iran. Materials and Methods: Data was collected from 314 midwives, specialist and also managers working in all public hospitals in 2016. The Cronbach's alpha coefficient was used to analyze psychometric features of the Safety Attitudes Questionnaire (SAQ). Results: $86.2 \%$ of the participants $(n=314)$ completed the questionnaire. Results showed that lower scores in teamwork, safety climate and also job satisfaction subcomponents. The working conditions and stress recognition had the highest negative scores. There was a significant relationship between the following subcomponents and work load: teamwork $(\mathrm{r}=-0.416, \mathrm{P}$-value $=$ $0.05)$, stress recognition $(r=0.40, P$-value $=0.05)$ and also working conditions $(\mathrm{r}=0.421 ; \mathrm{P}$-value $=0.02)$. The score of midwives was significantly lower than specialists regarding job satisfaction ( $\mathrm{P}$-value $=0.014$ ), working conditions $(\mathrm{P}$-value $=0.02)$ and also the overall safety attitude score $(\mathrm{P}$-value $=0.001)$. About $63 \%$ of respondents reported no error during the last year. The mean of error reporting during the last year significantly increased among specialists compared to midwives $(\mathrm{P}$-value $=0.001)$. Conclusion: Maternity care units in the region with high maternal death have been faced with many intangible barriers related to safety attitude such as poor teamwork climate, working condition and also poor stress recognition. It is now needed to promote supportive environment for midwives and also strengthening staff cohesion
\end{abstract}


through guiding the strategic direction of current maternity risk management system in creating open and just culture, improving leadership behaviors among senior managers and also addressing poor staffing levels.

\section{Keywords}

Safety Attitude, Maternity Care, Quality Care, Safety Culture, Risk Management

\section{Introduction}

Prevention of adverse events in maternity care is recognized as an essential priority for health care systems especially in developing countries [1] [2] [3]. It is noteworthy that maternal death is considered as the tip of an iceberg and women has been experienced reproductive morbidity 20 to 30 times more than normal range [3] [4]. Even in the countries with lower rate of maternal death, the nearmiss cases and severe maternal morbidity are still catastrophic [1] [2] [3] [4].

Iran has achieved a dramatically decline in the maternal mortality ratio that comparable with developed countries. According to the international reports, maternal death in Iran decreased 85\%, from 120 cases in 1990 to 25 cases in 2013 [1]. However, in some regions of Iran such as Ilam province, maternal death has been yet reported at 32 cases per 1000 live birth [5]. At the present, Iranian maternity care system is managed centrally and universities are responsible to implement Maternal Health Program and also regulations related to Mother-friendly Hospital in order to improve the quality of maternity care [6] [7] [8]. Medicalized care is the norm of hospitals and midwifery care is undervalued in the Iranian maternity care system, [9] as caesarian rate has been recently reported 48 percent [10]. Iranian maternity risk management system has been developed based on the analysis of root causes of near-miss cases and all universities have been obligated to promote the structure and processes of safety since 2008, [6]-[12] however the obstetrical errors are still common, [7] [8] To prevent adverse events, it is critical to take comprehensive and proactive approach in the maternity risk management system [13] [14] [15]. It seems that in the current maternity care system, organizational issues that contribute to unsafe conditions have not been assessed in order to change safety behaviors of staffs and to mitigate adverse events [8]. This study aimed to assess safety attitude in the maternity care units for the first time in public hospitals with high maternal death reporting.

\section{Methods and Materials}

Across-sectional survey of 364 staffs was conducted in all public hospitals (one relatively large, four median and three small hospitals) in Illam Province. During March to May, 2016, research midwives asked ward managers to distribute the questionnaires to staff and encourage completion. All managers, midwives, specialists and other staff who involved in the maternity care system were enrolled 
into the study. Staff returned questionnaire to research midwives from the wards for two months. Questionnaires were labelled with a code that allowed identification of the hospital and ward. Accordingly, the rate of responding was $86.2 \%$ and the study was conducted on 314 respondents.

Statistical analysis will carry out using the SPSS 16.0 software. Descriptive statistics such as frequencies, percentages for categorical variables and mean, standard deviation for continuous variables. The t-test and one way Anova were used to assess whether the means of groups were statistically different from each other and Pearson correlation coefficient was used to analyze the relation between continuous variables. P-value $<0.05$ is considered statistically significant.

Measurement tool: In the current study, we used Safety Attitudes Questionnaire (SAQ). This questionnaire was developed by Sexton B. et al. (2006) and assessed six safety-related climate domains including teamwork, safety climate, job satisfaction, perception of management, working conditions and stress recognition. Each item was scored based a 5 -point Likert scale $(1=$ strongly disagree, $2=$ slightly disagree, $3=$ not applicable, $4=$ slightly agree and $5=$ strongly agree) [16]. Total scores were graded from 0 to 100 and more than $75 \%$ was considered as positive. In this study, Persian translation and back translation into English of the SAQ was done independently by two persons with good command of English and overseen by an expert committee including obstetricians, midwives and patient safety experts. In this expert committee, questionnaires were reviewed based on a holistic and not a verbatim approach regarding the clarity of words and sentences. Experts suggested to ask three following questions were added to respondents' demographic information (age, job discipline, working experience, work load) and to determine staff perception related to safety.

1) Number of reported errors during the last 12 months based on: no error was reported, one or two errors were reported, three to five errors were reported, and more than six errors were reported.

2) What safety grade do you give to this unit?

3) What safety grade do you give to this hospital?

Face validity was then done by 24 midwives and 8 obstetrics that checked the questionnaire for comprehension. Finally, the clarity or ambiguity of translated words and sentences, their difficulty or ease were assessed in the committee and a few suggestions were given for revision. Psychometric evaluation of Persian version of SAQ showed the reliability and validity of SAQ among Persian language speaking staff. The Cronbach's alpha was acceptable at 0.78-0/86.

The research project was approved in the ethical committee of Iran University of Medical Sciences under the code: IR.IUMS.REC.1394.921137319. Ethical considerations were observed in designing and conducting current study.

\section{Results}

Three hundred and fourteen of staffs (86.2\%) completed the questioners. Most of them (82\%) were midwives, $86 \%$ were female and $90.8 \%$ were bachelor. 10 percent were specialists which most of them were obstetricians and 8 presents 
were managers. The mean age of participants was $33.52 \pm 6.37$ years. The mean of working experience in the maternity care units was $8.38 \pm 6.56$ years. Also the mean of working hours of participants was $49.53 \pm 14.78$ hours per week. The highest score in subdomains of safety attitude belonged to the following items: "I have the support from other staffs" $(62.3 \%)$, "It is easy for staffs here to ask questions when there is something that they do not understand" (61.8\%), "Midwives and specialists here work together as a well-coordinated team" (56.9\%), and the lower rates belonged to the following items: "Management supports my daily efforts" (32.7\%), "This hospital does a good job of training new staff" (37.5\%), "Trainees in my discipline are adequately supervised" (38\%). Subdomains such as teamwork and also safety climate had higher scores, but lower than 75 out of 100 which were considered as negative. The lowest scores in safety attitude belonged to subdomains as follows: working conditions $(56.60 \pm 23.21)$, stress recognition $(59.62 \pm 23)$ and also safety climate $(61 \pm 16.02)$. There was no significant relationship between the age, gender and hospital ward (labor, postpartum and operating room) and positive attitude toward safety, based on the variance analysis results (Table 1 ). But related to subdomains such as teamwork $(\mathrm{r}=-0.716, \mathrm{P}=0.05)$, stress recognition $(\mathrm{r}=-0.409, \mathrm{P}=0.051)$, perception of management $(\mathrm{r}=0.339, \mathrm{P}=0.02)$ and also working condition $(\mathrm{r}=-0.421, \mathrm{P}=$ 0.02 ) showed a significant negative correlation with workload.

The items with highest scores were the following: "I like my job" (82.18), "I would feel safe being treated here as a patient" (69.91), “it is easy for personnel in this clinical area to ask questions when there is something they do not understand" (67.36), "Morale in this clinical area/ unit is high" (66.90), "this hospital is a good place to work" (65.97). The items with the lower scores were: "this hospital deals constructively with problem physicians and personnel" (42.59), "hospital administration supports my daily efforts" (44.68), "I receive appropriate feedback about my performance" (46.06), "the levels of staffing in this clinical area are sufficient to handle the number of patients" (47.69), "I am more likely to make errors in tense or hostile situations" (47.69).

Table 2 shows a significant difference regarding the subdomain of job satisfaction among all groups. In the current study, the overall attitude of the staff toward safety was about $63 \% ; 65 \%$ and $62 \%$ of the respondents agreed that the grade of safety in the ward and also hospital were acceptable, respectively. Of course the grade of safety in the ward $(\mathrm{P}=0.05)$ and hospital $(\mathrm{P}=0.001)$ were significantly lower among midwives compared to the specialists. All respondents agreed that all domains of safety attitude had significant relationship with the grade of safety in the ward and also hospital $(P=0.001)$. In addition, $61 \%$ of the participants reported no error during the last year. In the current study, the mean of "not reporting any error" among the midwives was significantly lower than that of specialists during the last year $(\mathrm{P}$-value $=0.001)$. Also, there was a significant relationship between the frequency of error reporting and teamwork among all domains of safety attitude. 
Table 1. The mean and standard deviation of scores of safety attitudes and staff's demographic characteristics.

\begin{tabular}{|c|c|c|c|c|c|c|}
\hline \multirow[b]{2}{*}{ Variables } & \multicolumn{6}{|c|}{ Domains of attitude toward safety } \\
\hline & Teamwork & Safety climate & Job satisfaction & $\begin{array}{c}\text { Stress } \\
\text { recognition }\end{array}$ & $\begin{array}{l}\text { Perception of } \\
\text { management }\end{array}$ & $\begin{array}{l}\text { Working } \\
\text { conditions }\end{array}$ \\
\hline \multicolumn{7}{|l|}{ Gender } \\
\hline Female & $14.24 \pm 66.23$ & $15.82 \pm 61.23$ & $22.83 \pm 68.47$ & $23.47 \pm 59.56$ & $18.83 \pm 62.24$ & $23.33 \pm 56.42$ \\
\hline Male & $19 / 18 \pm 64.60$ & $17.25 \pm 61.67$ & $16.53 \pm 76.91$ & $20.50 \pm 59.97$ & $21.62 \pm 68.26$ & $22.78 \pm 57.53$ \\
\hline P-value & 0.493 & 0.863 & $* 0.004$ & 0.911 & 0.051 & 0.764 \\
\hline \multicolumn{7}{|l|}{ Education } \\
\hline Bachelor & $15.05 \pm 65.96$ & $16.13 \pm 61.37$ & $22.08 \pm 70.32$ & $23.30 \pm 59.75$ & $19.33 \pm 63.08$ & $23.33 \pm 56.61$ \\
\hline Master's degree or higher & $13.97 \pm 66.07$ & $15.44 \pm 60.79$ & $22.56 \pm 65.73$ & $20.81 \pm 58.63$ & $20.11 \pm 64.07$ & $22.64 \pm 56.49$ \\
\hline P-value & 0.969 & 0.843 & 0.256 & 0.790 & 0.780 & 0.977 \\
\hline \multicolumn{7}{|l|}{ Age (year) } \\
\hline under 30 & $60.23 \pm 10.64$ & $78 \pm 29.12 .64$ & $14.14 \pm 12.66$ & $93.79 \pm 13.65$ & $37.15 \pm 12.62$ & $41.28 \pm 16.54$ \\
\hline $30-40$ & $33.92 \pm 13.65$ & $14.65 \pm 14.61$ & $94.91 \pm 11.68$ & $45.67 \pm 4.69$ & $48.34 \pm 13.66$ & $35.28 \pm 12.60$ \\
\hline over 40 & $43.99 \pm 14.63$ & $61.26 \pm 12.64$ & $04.62 \pm 12.70$ & $40.54 \pm 11.61$ & $14.14 \pm 12.67$ & $41.28 \pm 14.59$ \\
\hline P-value & 0.326 & 0.189 & 0.345 & 0.457 & 0.904 & 0.765 \\
\hline \multicolumn{7}{|l|}{ Working experience (year) } \\
\hline Less than 5 & $41.10 \pm 13.61$ & $27.11 \pm 16.61$ & $23.79 \pm 11.62$ & $.3359 \pm 13.61$ & $.1454 \pm 11.60$ & $10.4323 \pm .61$ \\
\hline 5-10 & $35.13 \pm 10.63$ & $48.09 \pm 12.62$ & $45.47 \pm 4.60$ & $41.45 \pm 4.62$ & $24.63 \pm 10.63$ & $22.92 \pm 13.62$ \\
\hline More than 10 & $4115.18 \pm .62$ & $2411.12 \pm .60$ & $11.3064 \pm .61$ & $30.44 \pm 11.63$ & $04.22 \pm 14.61$ & $23.99 \pm 14.60$ \\
\hline $\mathrm{P}$-value & 0.13 & 0.110 & 0.800 & 0.346 & 0.518 & 0.975 \\
\hline \multicolumn{7}{|l|}{ Working hour (hours/week) } \\
\hline $40 \geq$ & $55.67 \pm 14.51$ & $63.55 \pm 14.51$ & $71.31 \pm 21.34$ & $66.31 \pm 23.55$ & $67.12 \pm 15.55$ & $61.41 \pm 11.24$ \\
\hline $40 \leq$ & $61.38 \pm 27.48$ & $61.62 \pm 12.02$ & $68.81 \pm 20.23$ & $57.01 \pm 11.87$ & $60.31 \pm 17.87$ & $52.01 \pm 12.17$ \\
\hline $\mathrm{P}$-value & $0.05^{\star}$ & 0.889 & 0.990 & $0.05^{*}$ & $0.029^{*}$ & $0.023^{*}$ \\
\hline \multicolumn{7}{|l|}{ Hospital ward } \\
\hline Labor & $66.76 \pm 13.92$ & $61.33 \pm 14.89$ & $71.18 \pm 21.26$ & $60.31 \pm 22.55$ & $64.83 \pm 17.96$ & $56.94 \pm 21.95$ \\
\hline Postpartum & $64.90 \pm 17.93$ & $62.71 \pm 18.19$ & $69.51 \pm 25.44$ & $57.01 \pm 22 / 87$ & $64.08 \pm 21.14$ & $59.08 \pm 24.89$ \\
\hline Operating room & $65.63 \pm 1.65$ & $60.05 \pm 15.90$ & $67.85 \pm 20.59$ & $60.77 \pm 23.89$ & $59.83 \pm 19.87$ & $53.97 \pm 23.74$ \\
\hline $\mathrm{P}$-value & 0.666 & 0.578 & 0.545 & 0.524 & 0.156 & 0.377 \\
\hline \multicolumn{7}{|l|}{ Safety grade ward- level } \\
\hline Poor & $57.62 \pm 17.38$ & $52.63 \pm 19.96$ & $57.82 \pm 27.30$ & $69.55 \pm 23.18$ & $54.84 \pm 20.46$ & $40.59 \pm 28.27$ \\
\hline Acceptable & $64.74 \pm 11.71$ & $59.77 \pm 13.12$ & $68.19 \pm 21.27$ & $61.80 \pm 22.76$ & $61.98 \pm 17.65$ & $56.32 \pm 20.96$ \\
\hline Very good & $74.04 \pm 11.48$ & $67.71 \pm 12.42$ & $75.00 \pm 18.18$ & $51.28 \pm 21.27$ & $71.61 \pm 16.96$ & $64.68 \pm 18.49$ \\
\hline Excellent & $69.00 \pm 25.08$ & $69.26 \pm 25.95$ & $85.40 \pm 16.57$ & $49.25 \pm 25.21$ & $66.43 \pm 23.50$ & $63.33 \pm 25.11$ \\
\hline P-value & $0.001^{\star}$ & $0.001^{*}$ & $0.001^{\star}$ & $0.001^{\star}$ & $0.001^{\star}$ & $0.001^{*}$ \\
\hline \multicolumn{7}{|l|}{ Safety grade- hospital level } \\
\hline Poor & $59 / 82 \pm 27 / 30$ & $54 / 84 \pm 20 / 46$ & $40 / 59 \pm 28 / 27$ & $59 / 63 \pm 19 / 96$ & $69 / 55 \pm 18 / 23$ & $57 / 62 \pm 16 / 38$ \\
\hline Acceptable & $66 / 19 \pm 18 / 27$ & $61 / 98 \pm 17 / 65$ & $56 / 32 \pm 20 / 96$ & $58 / 77 \pm 17 / 12$ & $61 / 80 \pm 22 / 76$ & $64 / 74 \pm 11 / 71$ \\
\hline Very good & $74 / 00 \pm 18 / 19$ & $71 / 61 \pm 16 / 96$ & $64 / 68 \pm 18 / 49$ & $67 / 71 \pm 12 / 48$ & $51 / 28 \pm 21 / 27$ & $74 / 04 \pm 12 / 48$ \\
\hline Excellent & $80 / 40 \pm 16 / 57$ & $66 / 43 \pm 23 / 50$ & $63 / 33 \pm 2 / 11$ & $69 / 26 \pm 21 / 95$ & $49 / 25 \pm 2 / 21$ & $69 / 00 \pm 24 / 08$ \\
\hline P-value & $<0.001^{*}$ & $<0.001^{\star}$ & $<0.001^{*}$ & $<0.001^{\star}$ & $<0.001^{*}$ & $<0.001^{*}$ \\
\hline \multicolumn{7}{|l|}{ Frequency of error reporting } \\
\hline None & $60.55 \pm 14.51$ & $60.56 \pm 16.11$ & $68.14 \pm 23.45$ & $59.59 \pm 22.75$ & $61.63 \pm 19.75$ & $55.42 \pm 24.49$ \\
\hline One or two & $65.62 \pm 12.02$ & $62.56 \pm 12.85$ & $74.91 \pm 17.97$ & $61.05 \pm 20.81$ & $68.42 \pm 12.06$ & $58.56 \pm 18.94$ \\
\hline Three to five & $64.65 \pm 15.39$ & $65.44 \pm 14.11$ & $72.38 \pm 16.00$ & $57.38 \pm 21.87$ & $64.97 \pm 19.60$ & $62.12 \pm 18.13$ \\
\hline More than six & $51.38 \pm 27.48$ & $50.79 \pm 26.23$ & $81.11 \pm 14.09$ & $54.16 \pm 29.81$ & $66.22 \pm 29.90$ & $58.33 \pm 26.67$ \\
\hline P-value & 0.28 & $0.01^{*}$ & $0.01^{*}$ & $0.06^{*}$ & $0.01^{*}$ & $0.04^{*}$ \\
\hline
\end{tabular}

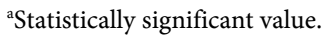


Table 2. Comparing the mean of positive safety attitude among staff.

\begin{tabular}{|c|c|c|c|c|c|}
\hline Variables & Mean \pm SD & $\begin{array}{l}\text { Managers }(n=25) \\
\quad \text { Mean } \pm S D\end{array}$ & $\begin{array}{l}\text { Specialists }(\mathrm{n}=31) \\
\text { Mean } \pm \mathrm{SD}\end{array}$ & $\begin{array}{c}\text { Midwives and other staff }(\mathrm{n}=257) \\
\text { Mean } \pm \text { SD }\end{array}$ & P-value \\
\hline Teamwork & $16.02 \pm 61.30$ & $68.40 \pm 10.12$ & $69.96 \pm 14.44$ & $65.28 \pm 14.56$ & 0.098 \\
\hline Safety climate & $16.02 \pm 61.30$ & $63.69 \pm 13.52$ & $64.05 \pm 12.71$ & $60.82 \pm 16.47$ & 0.370 \\
\hline Job satisfaction & $69.62 \pm 22.15$ & $75.41 \pm 12.33$ & $77.25 \pm 16.50$ & $57.61 \pm 23.33$ & $0.014^{*}$ \\
\hline Stress recognition & $59.62 \pm 23.00$ & $57.47 \pm 20.20$ & $59.80 \pm 20.31$ & $59.10 \pm 23.52$ & 0.294 \\
\hline Perception of management & $63.19 \pm 19.39$ & $73.11 \pm 16.62$ & $63.28 \pm 12.20$ & $61.15 \pm 19.58$ & $0.001^{*}$ \\
\hline Working conditions & $56.60 \pm 21.23$ & $61.45 \pm 15.39$ & $64.13 \pm 20.46$ & $54.65 \pm 23.90$ & $0.023^{*}$ \\
\hline Overall safety attitude & $63.23 \pm 12.62$ & $66.13 \pm 6.70$ & $68.90 \pm 11.33$ & $61.03 \pm 12.69$ & $0.001^{\star}$ \\
\hline \multicolumn{6}{|l|}{ Grade of safety-ward level } \\
\hline Poor & $34.83 \pm 21.26$ & $37.72 \pm 26.30$ & $33.83 \pm 24.46$ & $44.48 \pm 28.27$ & $0.001^{\star}$ \\
\hline Acceptable & $65.23 \pm 51.17$ & $62.38 \pm 15.65$ & $67.17 \pm 17.27$ & $55.52 \pm 20.96$ & \\
\hline \multicolumn{6}{|l|}{ Grade of safety (hospital level) } \\
\hline Poor & $38.17 \pm 17.27$ & $38.84 \pm 20.46$ & $38.68 \pm 28.27$ & $42.63 \pm 19.96$ & $0.05^{*}$ \\
\hline Acceptable & $61.92 \pm 23.65$ & $65.98 \pm 17.65$ & $64.32 \pm 20.96$ & $57.77 \pm 17.12$ & \\
\hline \multicolumn{5}{|l|}{ Frequency of error reporting } & 0001 * \\
\hline No error & $62.80 \pm 19.84$ & $55.67 \pm 16.38$ & $52.34 \pm 18.23$ & $67.42 \pm 24.49$ & $0.001^{\star}$ \\
\hline More than 3 errors & $36.23 \pm 16.71$ & $43.33 \pm 11.71$ & $47.76 \pm 22.76$ & $33.58 \pm 18.94$ & \\
\hline
\end{tabular}

A statistically significant value.

According to Table 2, there was a significant difference among professional groups regarding the job satisfaction subdomain. The Scheffe test indicated a significant difference regarding the job satisfaction in midwives compared to the specialists, and the mean score of this subdomain was significantly lower among midwives than specialists $(\mathrm{P}=0.01)$. Also, subdomain of working conditions and overall positive safety attitude was significantly lower among midwives than specialists $(\mathrm{P}=0.02)$. The score of perception of management was higher among managers and according to the Scheffe test, there was a significant difference between the score of managers and that of midwives regarding this subcomponent $(\mathrm{P}=0.01)$.

\section{Discussions}

The current study assessed the organizational barriers to improve safety in maternity care units from the viewpoint of midwives, specialists and also managers for the first time in Iran. This study also had some limitations. Although the response of participants was high, considering the small sample size, results of the current study could not be generalized. The findings of current study may be generalized to the subsystems with similar conditions. Hence, more studies should be performed based on size of hospital, number of patients admitted, and also accreditation status of hospital using multiple regression method to explore factors affecting improvement of staff-led reporting system and also safety attitude. 
According to the findings, improving safety in the maternity care units have been faced with barriers related to organizational culture which rooted in leadership, teamwork and also insufficient staffing levels. The score of safety climate which predicted error-reporting and also effective feedback system was low in this study which was in agreement with the findings of relevant studies [14]-[19]. In such a situation, staffs will be more prone to blaming each other when responding to adverse events and less likely to learn from error [19]. As, national reports and studies have emphasized that the current feedback system has not been effective for developing and maintenance of a high quality and safe maternity care [8] [9] [19]. It seems that Iranian maternity care system is mostly focused on "risk culture" approach than "safety culture" and following structure and strategies has not been changed based on supportive proactive approach. Low scores of subdomain of management perception, stress recognition, working conditions and also job satisfaction among staff were also reported in other similar studies [9] [19] [20]. These barriers were under the influence of poor supportive management, lack of leadership and also poor management of staff affairs, especially for the frontline staffs. Higher frequency of reporting errors by obstetrics compared of midwives might have been influenced by different two subcultures of obstetrics and midwifery system, relationship powers and also style of management in the current maternity care system. Further and more deeply studies should be conducted to explore which factors influenced on speaking up errors among midwives and specialists. However, it seems that structural and cultural issues such as weak authority of midwives and poor collaboration among midwives and specialists should be addressed through effective leadership and supportive management at all levels of system in order to improve staff behaviors.

\section{Conclusion}

Maternity care units in the region with high maternal death have been faced with many intangible barriers such as poor teamwork climate, working condition and also poor stress recognition. It is now needed to promote mutual respect, trust and staff cohesion and also to strengthen staff-led reporting system through guiding the strategic direction of risk management system in creating just and open culture, improving leadership behaviors among senior midwives managers and also addressing poor staffing affairs.

\section{Acknowledgements}

The current study was supported by the Deputy of Research and Technology of Iran University of Medical Sciences. The authors acknowledge their gratitude toward all managers and staff of Ilam hospitals who helped us with the current study, especially by completing the questionnaires.

\section{Conflict of Interests}

There was no conflict of interest. 


\section{References}

[1] WHO, World Bank, UNFPA and UNICEF (2014) Trends in Maternal Mortality: 1990 to 2013. World Health Organization, Geneva.

[2] Renfrew, M.J., McFadden, A., Bastos, M.H., Campbell, J., et al. (2014) Midwifery and Quality Care: Findings from a New Evidence Informed Framework for Maternal and Newborn Care. Lancet, 384, 1129-1145. https://doi.org/10.1016/S0140-6736(14)60789-3

[3] Firoz, T., Chou, D., von Dadelszen, P., Agrawal, P., et al. (2013) Measuring Maternal Health: Focus on Maternal Morbidity. Bulletin of the World Health Organization, 91, 794-796. https://doi.org/10.2471/BLT.13.117564

[4] Nair, M., Yoshida, S., Lambrechts, T., et al. (2014) Facilitators and Barriers to Quality of Care in Maternal, Newborn and Child Health: A Global Situational Analysis through Metareview. BMJ Open, 4, e004749.

https://doi.org/10.1136/bmjopen-2013-004749

[5] MOHME. National Maternal Health Program. Tehran: Ministry of Health and Medical Education.

[6] Changizi, N., Babaee, F., Ravaghi, H. and Farahani, Z. (2015) Obstetrics Risk Management in 5 Iranian Hospitals (Tehran-2012). Open Journal of Obstetrics and Gynecology, 5, 259-267. https://doi.org/10.4236/ojog.2015.55038

[7] Ministry of Health and Medical Education (2013) Report on 42 Maternal Death from Maternal Death Surveillance System. Tehran: Ministry of Health and Medical Education.

[8] Azemikhah, A., Amirkhani, M.A., Jalilvand, P., Emami Afshar, N., Radpooyan, L., Changizi, N. (2009) National Maternal Mortality Surveillance System in Iran. Iranian Journal of Public Health, 38, 90-92.

[9] Sabet, F., Shahshahan, Z., Heshmati, B. and Akbari, M. (2016) Cesarean Section Rate in Iran. Lancet, 388, 29-30. https://doi.org/10.1016/S0140-6736(16)30899-6

[10] Ministry of Health and Medical Education (2015) Regulation of Promotion of Natural Childbirth. Tehran: Ministry of Health and Medical Education.

[11] Yazdizadeh, B., Nedjat, S., Mohammad, K., Rashidian, A., Changizi, N. and Majdzadeh, R. (2011) Cesarean Section Rate in Iran, Multidimensional Approaches for Behavioral Change of Providers: A Qualitative Study. BMC Health Services Research, 11, 159. https://doi.org/10.1186/1472-6963-11-159

[12] Shekelle, P.G., Wachter, R.M., Pronovost, P.J., et al. (2013) Making Health Care Safer II: An Updated Critical Analysis of the Evidence for Patient Safety Practices. Comparative Effectiveness Review, No. 211. www.ahrq.gov/research/findings/evidence-based-reports/ptsafetyuptp.html

[13] Morello, R.T., Lowthian, J.A., Barker, A.L., et al. (2013) Purpose to Determine the Effectiveness of Patient Safety Culture Strategies to Improve Hospital Patient Safety Climate. BMJ Quality \& Safety, 22, 11-18. https://doi.org/10.1136/bmjqs-2011-000582

[14] Sandall, J., Christine, M. and Bick, D. (2010) Safety in Childbirth and the Three 'C's: Community, Context and Culture. Midwifery, 26, 481-482.

https://doi.org/10.1016/j.midw.2010.08.003

[15] Sexton, J.B., Helmreich, R.L., Neilands, T.B., Rowan, K., Vella, K., Boyden, J., Roberts, P.R. and Thomas, E.J. (2006) The Safety Attitudes Questionnaire: Psychometric Properties, Benchmarking Data, and Emerging Research. BMC Health Services Research, 6, 44. https://doi.org/10.1186/1472-6963-6-44

[16] Siassakos, D., Fox, R., Hunt, L., Farey, J., Laxton, C., Winter, C. and Draycott, T. 
(2011) Attitudes toward Safety and Teamwork in a Maternity Unit with Embedded Team Training. American Journal of Medical Quality, 26, 132-137. https://doi.org/10.1177/1062860610373379

[17] Sexton, J.B, Holzmueller, C.G, Pronovost, P.J., Thomas, E.J., McFerran, S., Nunes, J.,Thompson, D.A., Knight, A.P., Penning, D.H. and Fox, H.E. (2006) Variation in Caregive Perception of Teamwork Climate in Labor and Delivery Units. Journal of Perinatology, 26, 463-470. https://doi.org/10.1038/sj.jp.7211556

[18] Azami-Aghdash, S., Ebadifard Azar, F., Rezapour, A., Azami, A., Rasi, V. and Klvany, Kh. (2015) Patient Safety Culture in Hospitals of Iran: A Systematic Review and Meta-Analysis. Medical Journal of the Islamic Republic of Iran, 29, 251.

[19] Raftopoulos, V., Savva, N. and Papadopoulou, M. (2011) Safety Culture in the Maternity Units: A Census Survey Using the Safety Attitudes Questionnaire. BMC Health Services Research, 11, 238. https://doi.org/10.1186/1472-6963-11-238

[20] Royal College of Obstetricians and Gynecologists (2009) Improving Patient Safety: Risk Management for Maternity and Gynecology. Clinical Governance Advice No. 2.

Submit or recommend next manuscript to SCIRP and we will provide best service for you:

Accepting pre-submission inquiries through Email, Facebook, LinkedIn, Twitter, etc. A wide selection of journals (inclusive of 9 subjects, more than 200 journals)

Providing 24-hour high-quality service

User-friendly online submission system

Fair and swift peer-review system

Efficient typesetting and proofreading procedure

Display of the result of downloads and visits, as well as the number of cited articles

Maximum dissemination of your research work

Submit your manuscript at: http://papersubmission.scirp.org/

Or contact ojog@scirp.org 